\title{
The Hydra-Headed Coronaviruses: Implications of COVID-19 for Homeopathy
}

\author{
Silvia Waisse ${ }^{10} \quad$ Menachem Oberbaum $^{2}$ Michael Frass $^{3}$

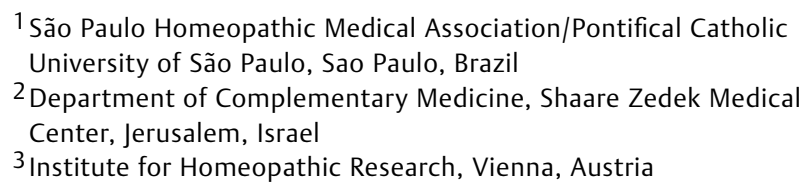

Address for correspondence Silvia Waisse, MD, PhD, R. Dr. Diogo de Faria 839, São Paulo, SP, Brazil (e-mail: dr.silvia.waisse@gmail.com).

Homeopathy 2020;109:169-175.

\begin{abstract}
Keywords

- coronavirus diseases

- homeopathy

- therapeutic approaches

- complex pandemics

Successful homeopathic prescriptions are based on careful individualization of symptoms, either for an individual patient or collectively in the case of epidemic outbreaks. The ongoing COVID-19 pandemic was initially represented as a severe acute respiratory illness, with eventual dramatic complications. However, over time it revealed to be a complex systemic disease with manifestations derived from viral-induced inflammation and hypercoagulability, thus liable to affect any body organ or system. As a result, clinical presentation is variable, in addition to variations associated with several individual and collective risk factors. Given the extreme variability of pathology and clinical manifestations, a single, or a few, universal homeopathic preventive medicine(s) do not seem feasible. Yet homeopathy may have a relevant role to play, inasmuch as the vast majority of patients only exhibit the mild form of disease and are indicated to self-care at home, without standard monitoring, follow-up, or treatment. For future pandemics, homeopathy agencies should prepare by establishing rapid-response teams and efficacious lines of communication.
\end{abstract}

\section{Introduction}

If coronavirus disease 2019 (COVID-19) has a striking characteristic, it is its puzzling nature. As in the Hydra myth, when experts believe to have taken hold of its head, a new and unexpected one seems to appear in its place.

Curious findings for a flu-like, viral pneumonia, such as indicators of hypercoagulability (elevated activated partial thromboplastin time, fibrinogen, and d-dimer levels), were reported among the earliest cases. By the end of April 2020, it had become clear that thrombo-inflammation is a striking feature of the pathophysiology of COVID-19. ${ }^{1-3} \mathrm{~A}$ patient admitted to our hospital by this time provides good illustration. A 3-month-old infant, she was one of only four children who tested positive for severe acute respiratory syndrome coronavirus 2 (SARS-CoV-2) at the Shaare Zedek Medical Center throughout the high-transmission period of the pandemic. She had started with a high fever 5 days prior to admission, without any other symptoms, not even loss of

received

May 5, 2020

accepted after revision

May 18, 2020

published online

July 22, 2020 appetite. Since the fever had not receded 3 days later, she was taken to a primary care provider and the due work-up was done which, given the times, also included the polymerase chain reaction (PCR) for SARS-CoV-2 RNA (ribonucleic acid). She was found to have a simple urinary tract infection, was prescribed oral antibiotics, and discharged. The following day, her parents received a telephone call and were informed their daughter had tested positive; thus they brought her back to hospital. On admission she had moderate fever $\left(38.2^{\circ} \mathrm{C}\right)$, normal vital signs and oxygen saturation, no abnormal findings on physical examination, leukocytosis (36.4 cells $/ \mu \mathrm{L}$ ) with neutrophilia, moderate thrombocytosis, and C-reactive protein $13.96(0-0.5 \mathrm{mg} / \mathrm{mL})$. By this time, Escherichia coli had grown in the urine sample culture. But "odd" findings were also identified: on admission fibrinogen was $976 \mathrm{mg} /$ $\mathrm{dL}$ (normal range, $200-500 \mathrm{mg} / \mathrm{dL}$ ) and d-dimer $1,076 \mathrm{ng} /$ $\mathrm{mL}(0-500 \mathrm{ng} / \mathrm{mL})$. These are indicative of blood clotting and are characteristically increased in many COVID-19
Copyright $\odot 2020$ The Faculty of Homeopathy
DOI https://doi.org/ 10.1055/s-0040-1714053. ISSN 1475-4916. 
patients. The child was treated with intravenous antibiotics and discharged 2 days later to ambulatory follow-up.

A few days later, media worldwide were reporting that SARS-CoV-2 in children had been associated in the United Kingdom with an inexplicably high incidence of clinical manifestations resembling Kawasaki disease and/or toxic shock syndrome (TSS), with similar cases reported in Italy, France and Belgium. ${ }^{4,5}$ According to an Italian pediatric cardiologist, colleagues in Spain and Portugal had mentioned a similar situation to him. ${ }^{6}$ Naturally, the first thing to do was to look for references in the literature. To our utter surprise and shock we found a paper in The Journal of Infectious Diseases entitled: "Association between a Novel

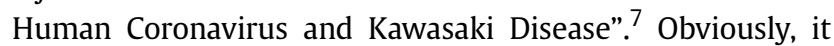
concerned children, as Kawasaki is a childhood disease. But the odd aspect is that this paper had been published 15 years earlier (this novel coronavirus was HCoV-NH [human coronavirus-New Haven], not the current coronavirus). We recalled that during the height of the pandemic, we had seen at our hospital several children with typical or atypical Kawasaki or undiagnosed Kawasaki-like conditions, as well as one case of TSS in an otherwise healthy child. An expert from New York City, Dr. Dyan Hes, stated on television, "I'm not surprised, because children who get a common cold, which is often caused by coronaviruses-the non-COVID-19-can get Kawasaki disease.... What we're learning more and more is that COVID-19 can cause just about any symptom and attack any part of the body but particularly in the vasculature-it causes a lot of inflammation". ${ }^{8}$ To be sure, very early in the course of the pandemic, many doctors had observed that COVID-19 evoked the macrophage activation syndrome. ${ }^{9}$

Like Dr. Hes, none of us should be surprised. But we are all surprised because from the very onset of the pandemic, the prevailing representation of COVID-19 was essentially that of an extremely aggressive flu-like, viral pneumonia with potentially dramatic complications, including acute respiratory distress syndrome (ARDS), septic shock, refractory metabolic acidosis, coagulation dysfunction, and multiple organ failure. ${ }^{10}$

This is also the representation of the disease adopted by homeopaths worldwide in their attempts to find not a cure for individual patients, but a universal preventive medicine, that is, the so-called genus epidemicus (GE) ${ }^{11-13}$

\section{Historia Magistra Vitae}

There is no need to delve here too deeply into the history of homeopathy in epidemics-the apparent success cases are repeated as a mantra by the global homeopathy community, ${ }^{14}$ from Hahnemann's treatment of scarlet fever in $1799,{ }^{15}$ to the more recent prevention of dengue fever in Brazil, ${ }^{16,17}$ and leptospirosis in Cuba in the 2010s. ${ }^{18}$ Therefore, it is worth looking closer into the "secret" of their success.

Hahnemann emphasized that the preventive remedy is the one able to quickly check a disease at its onset, not the remedy that cures it once it is fully developed. To illustrate, in the 1799 scarlet fever epidemic, he identified two forms of disease, a "mild" and a "severe", to be treated with opium and ipecacuanha respectively. In turn, patients with early, incipient (we would say prodromal) symptoms and healthy contacts were to be prescribed belladonna. ${ }^{19}$ The first lesson, therefore, is that the GE of COVID-19-or of any other disease for that matter-should be obtained from the earliest manifestations, that is, before pneumonia and the more severe complications set in. Whether in the present time we should also include laboratory data, such as liver function and coagulation profile for COVID-19, we leave it open for debate (our view is favorable-liver and thrombo-inflammation are already present and perceptible, albeit through means other than the human senses). The later stages (pneumonia and complications) should be regarded as a different disease, which should be analyzed separately for the corresponding curative (no longer preventive) treatment. However, the available data correspond exclusively to hospitalized, that is, severe and critical patients. This information does not serve to identify a homeopathic preventive remedy.

Going back to Hahnemann, each and every outbreak, he noted, should be fully investigated de novo, ${ }^{20}$ regardless of whether it or anything similar had ever previously appeared anywhere. Case definitions (suspect, probable, and confirmed cases) serve for epidemiological purposes, for example, to determine who should be tested, transmission rates, reproductive rates, and to plan the response. They also serve to distinguish between similar conditions. The following illustrates the point.

The history of the COVID-19 pandemic began in December 2019, when doctors in Wuhan, Hubei province, China, noticed clusters of viral pneumonia of unknown etiology. ${ }^{10}$ The causative agent was soon identified as a novel coronavirus; therefore attention focused on its similarities to and differences from two other coronaviruses that had recently triggered severe epidemic respiratory diseases, the severe acute respiratory syndrome (SARS) and the Middle East respiratory syndrome (MERS). ${ }^{21,22}$ This led to the idea of COVID-19 as essentially a respiratory disease, a form of pneumonia, to the extent that it is still called "COVID-19 pneumonia". ${ }^{10,23}$

According to Hahnemann, this approach is not at all useful in homeopathy: now we know that pneumonia develops later in the course of the disease and not in all the affected patientsapproximately $80 \%$ of infections are mild, while some may be altogether asymptomatic, ${ }^{24}$ and the vast majority of those infected do not develop pneumonia. Thus, it cannot be considered in the investigation of preventive GE medicine(s). What we know of SARS and MERS is not only unhelpful, but a confounding factor for homeopathy. We transcribe here an extremely elucidating warning by Hahnemann: "A careful examination will show that every prevailing disease is in many respects a phenomenon of a unique character, differing vastly from all previous epidemics, to which certain names have been falsely applied-with the exception of those epidemics resulting from a contagious principle that always remains the same, such as smallpox, measles, etc". ${ }^{20}$ As the most elementary literature search reveals, diseases by coronaviruses are pleiomorphic, and in no hypothesis can they be considered as "always remaining the same".

What must be done is to observe as many cases as needed until becoming familiar with the totality of signs and 
symptoms of any novel epidemic outbreak. Obtaining a characteristic portrait of the disease is the indispensable condition to find a suitable homeopathic medicine. Moreover, Hahnemann observes that clusters of patients infected from the same source exhibit similar clinical characteristics, but do not represent the full extent of the disease. ${ }^{25}$ Nunes' experience in Macaé, Rio de Janeiro, Brazil, with dengue fever provides appropriate confirmation. ${ }^{16}$

From 2007 to 2012, the Macaé municipal health secretariat included homeopathy in its standard management of epidemic and endemic dengue fever, through distribution of homeopathic medicines gratis to the entire city population with preventive intent. Outbreaks occurred in 2007 and 2010. In the first year (2007) the selected medication was a threecomponent formula derived from a pilot trial in São José do Rio Preto, São Paulo. For the following 5 years, medicines were selected based on careful analysis of the characteristic signs and symptoms of each outbreak at the local level. With this, in the second year (2008) for instance, incidence dropped $71 \%$ in Macaé, while it increased $273 \%$ to $3454 \%$ in the neighboring municipalities and $315 \%$ in the state of Rio de Janeiro as a whole. Mortality rate fell in 2010 to 0.68 , versus 1.86 to 4.76 for neighboring municipalities and 2.18 for the state as a whole.

In the case of COVID-19, instead, we find premature recommendations based on symptom descriptions taken from conventional doctors and national and international health agencies. These, as mentioned earlier, are biased toward influenza-like and respiratory symptoms, case definitions and, more seriously, they were obtained from severe and critical hospitalized patients (stages 2 and 3). A case in point is that of the recommendations by the International League of Homeopathic Doctors. ${ }^{11}$

Premature conclusions were drawn also in the first reports of attempts at homeopathic characterization of COVID-19. As an example, the unpublished study by Kasariyans and Sankaran of 18 patients (only eight described, only three reported as confirmed cases) rapidly travelled across the global community of homeopathic practitioners. ${ }^{26}$ For instance, the municipal secretariat of health of Itajaí, Santa Catarina, Brazil, has been offering the remedy suggested by these authors at primary care facilities since April 29, $2020 .^{27}$

Yet these authors were neither imprudent nor negligent: their conclusions were based on a construction of GE attributed to Kent-who never reported having treated a single epidemic outbreak of any disease, but was merely commenting on the indispensable need to individualize cases, both singly and collectively. Chapter 3 of the notes compiled by Kent's students and published as Lectures on Homeopathic Philosophy reads that observing just twenty patients suffices to obtain the image of any epidemic outbreak as it affects the entire "human race". ${ }^{28}$ In stark contrast, in the next section we discuss the extreme variability of COVID-19's clinical manifestations.

\section{A Kaleidoscopic Disease}

The ground-laying reports are those by Huang et al, ${ }^{29}$ Chen et $\mathrm{al}^{30}$ Guan et al, ${ }^{31}$ and Wang et al. ${ }^{32}$ The pattern they described is characterized by fever and dry cough, variable rates of fatigue, and characteristic abnormal findings on chest computed tomography. In turn, upper respiratory tract symptoms are almost negligible ( - Table $\mathbf{1}$ ).

With reports increasing, the China National Health Commission published a guideline, ${ }^{10}$ which has been periodically updated. We had access only to the 7th and last edition, published on March 4,2020, but as per citations in the literature the core seems practically unchanged with regard to clinical aspects. According to this document, the main manifestations of COVID-19 are fever, dry cough and fatigue. Other relevant symptoms include nasal obstruction, runny nose, sore throat, myalgia and diarrhea. Severely ill patients present dyspnea and/or hypoxemia 1 week after onset. The Commission comments that, remarkably, some severely ill patients present only mild- to moderate-grade fever throughout the course of disease, and some show no fever at all. Children and newborns present atypical symptoms, such as vomiting, diarrhea, and other gastrointestinal discomfort, or drowsiness and shortness of breath. Mild cases present lowgrade fever and slight fatigue, without evident pneumonia.

Both the Commission's and later the World Health Organization's ${ }^{33}$ definitions of suspect cases emphasize epidemiological history (travel to or residence in communities with documented COVID-19-positive cases or contact with COVID-19 patients within 14 days prior to the onset of symptoms) and the presence of acute respiratory illness (fever and respiratory symptoms). The Chinese also consider imaging features of COVID-19 pneumonia and normal or decreased leukocyte and lymphocyte counts. Confirmed cases are those with positive laboratory testing, particularly real-time PCR for SARS-CoV-2 RNA. Thus, any patient who does not present fever and/or respiratory symptoms/abnormal chest imaging is not considered a suspect case and is not included for targeted testing.

Yet, there is one intriguing aspect. The Chinese guidance lists the main differential diagnosis as being upper respiratory tract infection for mild cases, pneumonia by other causes (influenza, adenovirus, respiratory syncytial virus, Mycoplasma pneumoniae), and organizing pneumonia. However, according to the guidance, this stage of disease should also be distinguished from vasculitis syndromes (reasonable in light of the aforementioned considerations) and dermatomyositis, which seems inexplicable.

Published case series are too numerous to be individually analyzed (we retrieved all those included in PubMed and in the medRXiv database of articles under peer-review until April 28, 2020). Results are extremely variable, besides the fact they mainly report signs and symptoms of flu-like and respiratory illnesses, as expected from the definitions of the suspect case. Yet, after 4 months, there is a considerable number of systematic reviews with meta-analysis of cases inside and outside China. All, however, relate exclusively to hospitalized (severe and critical) patients-which represent the smallest proportion, approximately $20 \%$. In any case, these reviews (published until April 23, 2020) corroborate the original descriptions: only fever and cough are present in more than half of the patients, with fatigue closely following (30.442.0\%). ${ }^{34-37}$ Abnormal findings on chest imaging compatible 
172 Hydra-Headed Coronaviruses and Homeopathy Waisse et al.

Table 1 Symptoms at onset of the earliest COVID-19 patients

\begin{tabular}{|c|c|c|c|c|}
\hline & Huang et $\mathrm{al}^{28}$ & Chen et $\mathrm{al}^{29}$ & Wang et $\mathrm{al}^{31}$ & Guan et $\mathrm{al}^{30}$ \\
\hline Symptom & $n=41$ & $n=99$ & $n=138$ & $n=1,099$ \\
\hline Time frame & Until January 2 & January $1-20$ & January 1-28 & Until January 29 \\
\hline Fever & $98 \%$ & $83 \%$ & $98.6 \%$ & $\begin{array}{l}\text { On admission } 43.8 \% \\
\text { During hospitalization } 88.7 \%\end{array}$ \\
\hline Cough & $76 \%$ & $82 \%$ & $59.4 \%$ & $67.8 \%$ \\
\hline Myalgia/fatigue & $44 \%$ & $11 \%$ & $34.8 \% / 69.6 \%$ & $3.8 \% / 38.1 \%$ \\
\hline Sputum production & $28 \%$ & NR & $26.8 \%$ & $33.7 \%$ \\
\hline Headache & $8 \%$ & $8 \%$ & $6.5 \%$ & $13.6 \%$ \\
\hline Hemoptysis & $5 \%$ & NR & & $38.1 \%$ \\
\hline Diarrhea & & $2 \%$ & $10.1 \%$ & $3.5 \%$ \\
\hline Shortness of breath & $\begin{array}{l}\text { None on admission } \\
55 \% \text { during stay at hospital }\end{array}$ & $31 \%$ & $31.2 \%$ & $18.7 \%$ \\
\hline Confusion & & $9 \%$ & & \\
\hline Sore throat & & $5 \%$ & $17.4 \%$ & $13.9 \%$ \\
\hline Rhinorrhea & & $4 \%$ & & \\
\hline Chest pain & & $2 \%$ & & \\
\hline Nausea and/or vomiting & & $1 \%$ & $10.1 \% / 3.6 \%$ & $4.6 \%$ \\
\hline Conjunctival congestion & & & & $0.8 \%$ \\
\hline Nasal congestion & & & & $4.8 \%$ \\
\hline Chills & & & & $11.5 \%$ \\
\hline Anorexia & & & $39.9 \%$ & \\
\hline Dizziness & & & $9.4 \%$ & \\
\hline Abdominal pain & & & $2.2 \%$ & \\
\hline Pneumonia on imaging & $100 \%$ & $\begin{array}{l}75 \% \text { bilateral } \\
25 \% \text { unilateral }\end{array}$ & $100 \%$ & $86.2 \%$ \\
\hline
\end{tabular}

Abbreviations: COVID-19, coronavirus disease-2019; NR, not reported. Note: bold $>50 \%$.

with COVID-19 were reported for 88.2 to $96.6 \%$ of patients. According to a recent summary, most patients present more than one symptom on admission, but the combination of fever, cough, and shortness of breath is rare. ${ }^{38}$

As of late, it has been widely acknowledged that, despite very low oxygen saturations (as low as 50\%), many COVID-19 patients are comfortable and do not exhibit dyspnea, as is the case of mountain climbers. ${ }^{39}$ This condition, dubbed "silent hypoxia" or "happy hypoxia", is understandable when one considers that the basic lung injury is vascular microthrombosis: ${ }^{3}$ that is, a disorder of the alveolar perfusion rather than of ventilation. It is thus not by chance that Italian intensivists learned to distinguish two populations of critical patients: a "silent" hypoxemia group with severe hypoxemia and near normal respiratory system compliance (a combination rarely seen in severe ARDS), and a remarkably dyspneic, normo/hypercapnic group. ${ }^{40}$

There is, however, far more to consider. A steadily increasing number of studies report potential transmission routes other than air droplets-among them, fecal-oral and tears-as well as extra-respiratory symptoms as initial manifestations of disease. This being the case, it can be inferred that when such patients do not present fever or respiratory problems, they are not considered for testing and are never diagnosed with COVID-19. On these grounds, Li et al estimated that up to $86 \%$ of cases in China may have been missed. ${ }^{41}$

\section{Extra-Respiratory Manifestations}

- Neurological signs: ischemic or hemorrhagic stroke, musculoskeletal disorders, impaired consciousness, ${ }^{42,43}$ GuillainBarré syndrome, acute hemorrhagic necrotizing encephalopathy, ${ }^{44,45}$ acute meningoencephalitis, ${ }^{46}$ and acute disseminated encephalomyelitis. ${ }^{47}$ It is worth mentioning a recently reported striking series of young patients with largevessel stroke as presenting feature of COVID-19.48

- Ocular signs: conjunctival hyperemia, chemosis, and increased secretion. ${ }^{49,50}$

- Acute onset anosmia-a/hypo/dysgeusia: incidence of up to $53 \%$, and significantly higher than in control influenza cases. $^{51}$ These symptoms were included by the U.S. Centers of Disease Control as a suspect-case criterion on April 24, 2020. ${ }^{52}$

- Cardiovascular symptoms: myocardial injury, ${ }^{53-55}$ myocarditis, myopericarditis, ${ }^{56}$ arrhythmia, and heart failure. ${ }^{53}$ 
- Gastrointestinal symptoms: incidence of 3.0 to $79.0 \%$ appearing as initial or even single manifestation. ${ }^{57-59}$

- Hepatic symptoms: abnormal liver function in almost half of the cases, representing liver cell, rather than bile duct injury-despite the high expression of angiotensinconverting enzyme 2 (ACE2) in the latter. ${ }^{60,61}$

- Spleen and lymphatic dysfunction: direct infection via tissue-resident CD169+ macrophages-which express ACE2, with severe tissue damage. ${ }^{62}$

- Dermatological signs: reports are still contentious, while pernio (chilblains, "COVID toes") is currently discussed in the mass media. The American Academy of Dermatology has an open registry to collect data.

Vetter et al thus summarize the current picture: the working case definition to select people for viral testing imperfectly identifies patients without respiratory symptoms or with only very mild symptoms. ${ }^{44}$ Tosato et al are even more daring: "COVID-19 is a multifaceted, chameleonic, and complex viral infection that can cause discordant features in its initial phase". 63

\section{Lessons Learned and Recommendations}

Coronaviruses (sub-family Coronavirinae, family Coronaviridae, order Nidovirales) comprise four genera, Alpha-, Beta-, Gammaand Delta-coronavirus, of which the former two are known to cause respiratory illness in humans and gastroenteritis in animals. $^{64}$ SARS-CoV-1 and MERS-CoV cause severe respiratory illness in humans, while the other four human coronaviruses (HCoV-NL63, HCoV-229E, HCoV-OC43, and HKU1) are associated with mild upper respiratory diseases, but eventually also lead to severe infections in infants, young children, and older adults. MERS-CoV uses dipeptidyl peptidase 4 (DPP4/CD26) as receptor, whilst SARS-CoV-1 uses ACE2, as do HCoV-NL63 and SARS-CoV-2. ${ }^{65,66}$

ACE2 is widely distributed throughout the human body. ACE2 messenger RNA is present in virtually all organs, and its protein is expressed mainly on lung alveolar epithelial cells and small intestine enterocytes, in addition to arterial and venous endothelial cells and arterial smooth muscle cells in at least the brain, skin, oral and nasal mucosa, nasopharynx, gastric cardia and corpus, spleen, thymus, lymph nodes, bone marrow, liver and kidneys. ${ }^{66}$ It has been associated with the regulation of cardiac function and blood pressure, and is plentifully expressed in the placenta, indicating a role in the maternal-fetal interaction. ${ }^{65}$ This widespread distribution of ACE2 may help explain the multifarious pathogenicity of SARS-CoV-2.

Four months into the current pandemic, it is universally acknowledged that COVID-19 is no mere pneumonia or respiratory illness, but a complex polymorphic disease, with the potential to affect any body organ and system. Even when the same organ is involved, manifestations vary as a function of factors still to be elucidated. COVID-19 therefore does not seem to be a single disease, but a full range of pathological conditions having viral-induced inflammation and thrombosis in common. The manifestations exhibited by patients also vary as a function of age, which partially conditions their immune response, and at least mortality is known to be influenced by sex. ${ }^{67}$ Outcomes further depend on several risk factors (hypotension, diabetes, coronary artery disease, and chronic respiratory diseases), with viral load an independent risk factor. $^{38}$ All these, in different combinations, paint numerous clinical pictures that are being gradually identified.

COVID-19 is nothing like the known epidemic diseases, characterized by typical (pathognomonic) signs, symptoms, and clinical course. Attempting to identify a single preventive GE medicine, or even a few, is therefore a Sisyphean task.

What, then, could be the role of homeopathy in future epidemics, especially when the microorganism is pleiomorphic? In COVID-19, homeopathy has played a very small part in population-based initiatives to date, except in India, Cuba and Brazil, ${ }^{27,68-70}$ with still unknown outcomes, since data are still being collected.

From the research perspective, the gold standard is randomized clinical trials. At this moment, one is being conducted in India, ${ }^{71}$ and another was granted ethical clearance in Brazil-investigators are currently dealing with recruitment issues (personal communication). These are trials of individualized homeopathy to measure clinical outcomes (progression to severe/critical stage, need of mechanical ventilation, death).

While this type of study is useful to measure effectiveness/efficacy, it is not helpful to guide practice. In the case of COVID-19, homeopathic practitioners worldwide are providing individual care to outpatients, a group that represents approximately $80 \%$ of all cases. Many registries are opened to gather this experience, which cannot be seen as dismissible, inasmuch as the group of mild COVID-19 patients usually remain in home isolation without medical monitoring, follow-up, or treatment other than over-thecounter drugs (fever reducers, etc.).

Homeopathy could contribute far more if its local, regional, national, and international bodies organize rapid-response teams and established lines of communication. At the same time, these bodies should strive to improve interaction with mainstream medicine to work together. A good point of departure could be the departments of integrative medicine already available at the best hospitals in the world, usually with focus on cancer patients. Through proactive dialogue, the Department of Complementary Medicine at Shaare Zedek Medical Center, in Jerusalem, was granted ethical clearance to treat hospitalized, severe, non-critical COVID-19 patients as a pilot study. Another interesting path of interaction is that of medical residency programs. There has been one since 2014 at the Regional Public Hospital of Betim, Minas Gerais, Brazil, where homeopathy has been part of the standard care provided in public health services since 1996 (personal communication). As part of the regular hospital medical staffing, homeopathy residents and their supervisors treat inpatients in all specialty wards, including adult and pediatric intensive care and the neonatology department. Treatment of COVID-19 patients thus 
became a natural part of their tasks, which was extended to the local COVID-19 field hospitals. All these initiatives suggest that assimilation into the institutions of mainstream medicine seems a promising strategy to integrate homeopathy formally into health care systems.

\section{Highlights}

- COVID-19 was originally represented as an acute severe respiratory disease.

- In time it has proved to be a complex systemic condition liable to affect any body organ or system.

- As a result, it exhibits a complex scope of pathology and clinical manifestations.

- The complex nature of COVID-19 does not seem amenable to the genus epidemicus approach in homeopathy.

\section{Conflict of Interest}

None declared.

\section{Acknowledgments}

The authors thank Dr. Luiz Darcy, president of the Brazilian Medical Homeopathic Association, and Dr. Monica Beier, coordinator of the medical residency program in homeopathy in Betim, Minas Gerais, Brazil, for the information shared with us. We also thank the Shaare Zedek Medical Center, Jerusalem, Israel, for its support.

\section{References}

1 Connors JM, Levy JH. Thromboinflammation and the hypercoagulability of COVID-19. J Thromb Haemost 2020. Doi: $10.1111 /$ jth.14849

2 Negri EM, Piloto BM, Morinaga LK, et al. Heparin Therapy Improving Hypoxia in COVID-19 Patients: A Case Series. NY: medRxiv; 2020. Preprint Doi: 10.1101/2020.04.15.20067017

3 Dohlnikoff M, Duarte-Neto AN, Monteiro RAA, et al. Pathological evidence of pulmonary thrombotic phenomena in severe COVID19. J Thromb Haemost 2020;18:1517-1519

4 Woodyatt A, Howard J. Coronavirus could be tied to a rare but serious illness in children, UK doctors say. CNN. 27 Apr 2020 18:43 GMT. Available at: https://edition.cnn.com/2020/04/27/ health/children-covid-19-illness-intl-scli-gbr/index.html. Accessed April 29, 2020

5 Cheng M. European doctors warn rare kids' syndrome may have coronavírus tie. USA Today. Available at: https://www.usatoday. com/story/news/world/2020/04/28/coronavirus-doctors-warnkawasaki-disease-may-have-covid-19-tie/3038537001/. Accessed April 29, 2020

6 Reuters. Italy, UK explore possible COVID-19 link to Kawasaki disease in children. Available at: https://www.jpost.com/ international/italy-uk-explore-possible-covid-19-link-tokawasaki-disease-in-children-626133. Accessed April 29, 2020

7 Esper F, Shapiro ED, Weibel C, Ferguson D, Landry ML, Kahn JS. Association between a novel human coronavirus and Kawasaki disease. J Infect Dis 2005;191:499-502

8 Elkind E. Pediatrician explains why she's "not surprised" the coronavirus is being linked to a rare disease in children. CBS News. Available at: https://www.cbsnews.com/news/coronaviruskawasaki-rare-disease-children-pediatrician-dyan-hes/. Accessed April 29, 2020

9 Mehta P, McAuley DF, Brown M, Sanchez E, Tattersall RS, Manson JJ; HLH Across Speciality Collaboration, UK. COVID-19: consider cytokine storm syndromes and immunosuppression. Lancet 2020;395:1033-1034

10 China National Health Commission. Chinese clinical guidance for COVID-19 pneumonia diagnosis and treatment. 7th ed. Available from American College of Cardiology. Available at: https://www. acc.org/latest-in-cardiology/articles/2020/03/17/11/22/chineseclinical-guidance-for-covid-19-pneumonia-diagnosis-andtreatment. Accessed April 29, 2020

11 LMHI Executive Committee Communication Regarding Corona virus Epidemic. Available at: http://www.lmhi.org/Home/Corona. Accessed April 29, 2020

12 Central Council for Research in Homoeopathy. Ministry of AYUSH. Government of India. Homoeopathic perspectives in COVID-19 coronavirus infection. Available at: https://www.ccrhindia.nic.in/ WriteReadData/LINKS/Coronavirus\%20factsheet\%2001b7d849cd23-4d26-b520-685cba275c38.pdf. Accessed April 29, 2020

13 Associação Médica Homeopática Brasileira. Estudo preliminar de sintomas e medicamentos prevalentes do "gênio epidêmico" da pandemia. Available at: https://amhb.org.br/wp-content/uploads/ 2020/04/Estudo-Preliminar-do-Ge\%CC\%82nio-Epide\%CC\%82micocapa-e-timbre-AMHB.pdf. Accessed April 29, 2020

14 Jacobs J. Homeopathic prevention and management of epidemic diseases. Homeopathy 2018;107:157-160

15 Waisse S. The science of high dilutions in historical context. Homeopathy 2012;101:129-137

16 Nunes LAS. Homeopathy and dengue: Macaé, Rio de Janeiro, Brazil, 2007-2012. Rev Homeopatia 2016;79:1-16

17 Prass-Santos C, Brina NT, Magalhães IL, et al. Report on the use of homeopathic medication in the prophylaxis of dengue in Belo Horizonte, Minas Gerais, Brazil, in 2010. Rev Homeopatia 2012; $75: 1-12$

18 Bracho G, Varela E, Fernández R, et al. Large-scale application of highly-diluted bacteria for leptospirosis epidemic control. Homeopathy 2010;99:156-166

19 Hahnemann S. Heilung und Verhütung des Scharlach-Fiebers. In: Schmidt JM, Kaiser D, eds. Samuel Hahnemann: Gesammelte kleine Schriften. Heidelberg: Karl F. Haug; 2001:299-311

20 Hahnemann S. Organon of Medicine. 6th ed. New Delhi: B. Jain; 2005: $\$ 100$

21 Wang Y, Wang Y, Chen Y, Qin Q. Unique epidemiological and clinical features of the emerging 2019 novel coronavirus pneumonia (COVID-19) implicate special control measures. J Med Virol 2020. Doi: 10.1002/jmv25748

$22 \mathrm{Xu} \mathrm{YH}$, Dong JH, An WM, et al. Clinical and computed tomographic imaging features of novel coronavirus pneumonia caused by SARS-CoV-2. J Infect 2020;80:394-400

$23 \mathrm{Wu} \mathrm{Z}$, McGoogan JM. Characteristics and important lessons from the coronavirus disease 2019 (COVID-19) outbreak in China. Summary of a report of 72314 cases from the Chinese Center for Disease Control and Prevention. JAMA 2020; 323:1239-1242

24 Johns Hopkins ABC. Guide. Coronavirus COVID-19 (SARS-CoV-2). Available at: https://www.hopkinsguides.com/hopkins/view/ Johns_Hopkins_ABX_Guide/540747/all/ Coronavirus_COVID_19_SARS_CoV_2_. Accessed April 29, 2020

25 Hahnemann S. Organon of Medicine. 6th ed. New Delhi: B. Jain Publishers; 2005:§§102, 241

26 Kasariyans A, Sankaran R. Homeopathy for coronavírus COVID-19 infection. Available at: https://hpathy.com/homeopathy-papers/ homeopathy-for-coronavirus-covid-19-infection

27 Itajaí distribui a partir de quarta-feira homeopatia para melhorar imunidade. O Globo, 28 April 2020. Available at: https://g1.globo. $\mathrm{com} / \mathrm{sc} /$ santa-catarina/noticia/2020/04/28/itajai-distribuiapartir-de-quarta-feira-homeopatia-para-melhorar-imunidade. ghtml. Accessed April 29, 2020

28 Kent JT. Lectures on Homoeopathic Philosophy. Chicago: Ehrhart \& Karl; 1919 
29 Huang C, Wang Y, Li X, et al. Clinical features of patients infected with 2019 novel coronavirus in Wuhan, China. Lancet 2020; 395:497-506

30 Chen N, Zhou M, Dong X, et al. Epidemiological and clinical characteristics of 99 cases of 2019 novel coronavirus pneumonia in Wuhan, China: a descriptive study. Lancet 2020;395:507-513

31 Guan WJ, Ni ZY, Hu Y, et al; China Medical Treatment Expert Group for Covid-19. Clinical characteristics of coronavirus disease 2019 in China. N Engl J Med 2020;382:1708-1720

32 Wang D, Hu B, Hu C, et al. Clinical characteristics of 138 hospitalized patients with 2019 novel coronavirus-infected pneumonia in Wuhan, China. JAMA 2020;323:1061-1069

33 World Health Organization. Global surveillance for COVID-19 caused by human infection with COVID-19 virus. Interim guidance. 20 March 2020. Available at: https://www.who.int/ publications-detail/global-surveillance-for-human-infectionwith-novel-coronavirus-(2019-ncov. Accessed April 29, 2020

34 Fang Z, Yi F, Wu K, et al. Clinical Characteristics of Coronavirus Disease 2019 (COVID-19); Clinical characteristics of coronavirus disease 2019 (COVID-19); an updated systematic review. NY: medRXiv; 2020. Preprint Doi: 10.1101/2020.03.07.20032573

35 Sun P, Qie S, Liu Z, et al. Clinical characteristics of 50466 patients with 2019-nCoV infection. NY: medRXiv; 2020. Preprint Doi: $10.1101 / 2020.02 .18 .20024539$

36 Tang C, Zhang K, Wang W, et al. Clinical characteristics of 20,662 patients with COVID-19 in Mainland China: a systemic review and meta-analysis. NY: medRXiv; 2020. Preprint Doi: 10.1101/2020.04.18. 20070565

37 Heydari K, Rismantab S, Shamshirian A, et al. Clinical and paraclinical characteristics of COVID-19 patients: a systematic review and meta-analysis. NY: medRxiv; 2020. Preprint Doi: 10.1101/2020.03.26.20044057

38 Aguilar RB, Hardigan P, Mayi B, et al. Current understanding of COVID-19 clinical course and investigational treatments. NY: medRXiv; 2020. Preprint Doi: 10.1101/2020.04.19.20071548

39 Couzin-Frankel J. The mystery of the pandemic's 'happy hypoxia'. Science 2020;368:455-456

40 Gattinoni L, Chiumello D, Caironi P, et al. COVID-19 pneumonia: different respiratory treatments for different phenotypes? Intensive Care Med 2020;46:1099-1102

41 Li R, Pei S, Chen B, et al. Substantial undocumented infection facilitates the rapid dissemination of novel coronavirus (SARSCoV-2). Science 2020;368:489-493

42 Mao L, Jin H, Wang M, et al. Neurologic manifestations of hospitalized patients with coronavirus disease 2019 in Wuhan, China. JAMA Neurol 2020;77:683-690

43 Li Y, Wang M, Zhou Y, et al. Acute cerebrovascular disease following COVID-19: a single center, retrospective, observational study. Lancet-preprints (SSRN) 2020. Doi: 10.2139/ssrn.3550025

44 Vetter P, Vu DL, L'Huillier AG, Schibler M, Kaiser L, Jacquerioz F. Clinical features of covid-19. BMJ 2020;369:m1470

45 Poyiadji N, Shahin G, Noujaim D, Stone M, Patel S, Griffith B. COVID-19-associated acute hemorrhagic necrotizing encephalopathy: CT and MRI features. Radiology 2020. Doi: 10.1148/radiol.2020201187

46 Bernard-Valet R, Pizzarotti B, Anichini A, et al. Two Patients with Acute Meningo-encephalitis Concomitant to SARS-CoV-2 Infection. NY: medRXiv; 2020. Preprint Doi: 10.1101/2020.04.17.20060251

47 Zhang T, Rodricks MB, Hirsh E. COVID-19-Associated Acute Disseminated Encephalomyelitis-A Case Report. NY: medRxiv; 2000. Preprint Doi: $10.1101 / 2020.04 .16 .20068148$

48 Oxley TJ, Mocco J, Majidi S, et al. Large-vessel stroke as a presenting feature of COVID-19 in the young. N Engl J Med 2020;382:e60

$49 \mathrm{Wu}$ P, Duan F, Luo C, et al. Characteristics of ocular findings of patients with coronavirus disease 2019 (COVID-19) in Hubei Province, China. JAMA Ophthalmol 2020;138:575-578

50 Zhang X, Chen X, Chen L, et al. The evidence of SARS-CoV-2 infection on ocular surface. Ocul Surf 2020;18:360-362
51 Beltrán-Corbellini Á, Chico-García JL, Martínez-Poles J, Rodríguez-Jorge F, Alonso-Cánovas A. Reply to letter: Acuteonset smell and taste disorders in the context of Covid-19: a pilot multicenter PCR-based case-control study. Eur J Neurol 2020. Doi: $10.1111 /$ ene. 14273

52 US Centers for Disease Control and Prevention. Coronavirus disease 2019 (COVID-19). Symptoms of coronavirus. Available at: https://www.cdc.gov/coronavirus/2019-nCoV/hcp/clinicalcriteria.html. Accessed April 29, 2020

53 Shi S, Qin M, Shen B, et al. Association of cardiac injury with mortality in hospitalized patients with COVID-19 in Wuhan, China. JAMA Cardiol 2020. Doi: 10.1001/jamacardio.2020.0950

54 Guo T, Fan Y, Chen M, et al. Cardiovascular implications of fatal outcomes of patients with coronavirus disease 2019 (COVID-19). JAMA Cardiol 2020. Doi: 10.1001/ jamacardio.2020.1017

55 Yang C, Jin Z. An acute respiratory infection runs into the most common noncommunicable epidemic-COVID-19 and cardiovascular diseases. JAMA Cardiol 2020. Doi: 10.1001/jamacardio.2020.0934

56 Inciardi RM, Lupi L, Zaccone G, et al. Cardiac involvement in a patient with coronavirus disease 2019 (COVID-19). JAMA Cardiol 2020. Doi: $10.1001 /$ jamacardio.2020.1096

57 An P, Chen H, Jiang X, et al. Clinical features of 2019 novel coronavirus pneumonia presented gastrointestinal symptoms but without fever onset. Lancet-Preprints (SSRN) 2020. Doi: $10.2139 /$ ssrn.3532530

58 Han C, Duan C, Zhang S, et al. Digestive symptoms in COVID-19 patients with mild disease severity: clinical presentation, stool viral RNA testing, and outcomes. Am J Gastroenterol 2020;115:916-923

59 Pan L, Mu M, Yang P, et al. Clinical characteristics of COVID-19 patients with digestive symptoms in Hubei, China: a descriptive, crosssectional, multicenter study. Am J Gastroenterol 2020;115:766-773

60 Fan Z, Chen L, Li J, et al. Clinical features of COVID-19-related liver functional abnormality. Clin Gastroenterol Hepatol 2020; 18:1561-1566

61 Zhang Y, Zheng L, Liu L, Zhao M, Xiao J, Zhao Q. Liver impairment in COVID-19 patients: a retrospective analysis of 115 cases from a single centre in Wuhan city, China. Liver Int 2020 Doi: 10.1111/liv.14455

62 Feng Z, Diao B, Wang R, et al. The Novel Severe Acute Respiratory Syndrome Coronavirus 2 (SARS-CoV-2) Directly Decimates Human Spleens and Lymph Nodes. NY: medRXiv; 2020. Preprint Doi: $10.1101 / 2020.03 .27 .20045427$

63 Tosato F, Giraudo C, Pelloso M, Musso G, Piva E, Plebani M. One disease, different features: COVID-19 laboratory and radiological findings in three Italian patients. Clin Chem Lab Med 2020;58:1149-1151

64 Cui J, Li F, Shi ZL. Origin and evolution of pathogenic coronaviruses. Nat Rev Microbiol 2019;17:181-192

65 Hamming I, Timens W, Bulthuis MLC, Lely AT, Navis G, van Goor H. Tissue distribution of ACE2 protein, the functional receptor for SARS coronavirus. A first step in understanding SARS pathogenesis. J Pathol 2004;203:631-637

66 Hamming I, Cooper ME, Haagmans BL, et al. The emerging role of ACE2 in physiology and disease. J Pathol 2007;212:1-11

67 The Lancet. Editorial. The gendered dimensions of COVID-19. Lancet 2020;395:1168

68 Government of India. Press Information Bureau. AYUSH. Advisory for corona virus. Available at: https://pib.gov.in/PressReleasePage. aspx?PRID=1600895. Accessed April 30, 2020

69 INFOMED. Homeopatía y la aprobación del PrevengHo®Vir. Available at: https://temas.sld.cu/coronavirus/2020/04/08/homeopatia-y-laBrazil. Municipal Government of Betim, Minas Gerais. Homeopatia é aliada contra a COVID-19 em Betim. Available at: http://www. betim.mg.gov.br/noticias/43963\%3B50103\%3B06\%3B9808\% 3B184295.asp. Accessed May 13, 2020

71 Clinical Trials Registry - India. Proving the efficacy of homeopathic treatment in prevention and cure of COVID-19. Available at: http://ctri.nic.in/Clinicaltrials/pmaindet2.php? trialid=43212\&EncHid=\&userName=homeopathy. Accessed May 13,2020 